\title{
Educação e políticas de combate à pobreza*
}

\author{
Maria Malta Campos
}

Pontifícia Universidade Católica de São Paulo. Fundação Carlos Chagas

Em seu livro A nova era das desigualdades, Fitoussi e Rosanvallon constatam que "A questão social se aborda com demasiada frequiência em termos que combinam três grandes perversões da política moderna: a confusão da política com os bons sentimentos, o gosto pela política espetáculo e a simplificação dos problemas" (1997, p. 24).

Parece-me que muitas propostas de política social, que hoje tocam direta ou indiretamente a educação no país, podem ser encaixadas nessa caracterização desses autores. Penso que esse tema requer maior atenção dos intelectuais da educação do que tem merecido até agora; também aí a realidade atropela a agenda acadêmica, trazendo novas perplexidades ao campo já conturbado das políticas educacionais. Neste artigo, pretendo tão-somente ressaltar, em uma exploração ainda preliminar, algumas das principais ques-

* Trabalho apresentado na sessão especial "Políticas sociais para a infância e a juventude", na $26^{\text {a }}$ Reunião Anual da ANPEd, realizada em Poços de Caldas, MG, de 5 a 8 de outubro de 2003. tões que surgem no atual panorama das políticas sociais voltadas para o combate à pobreza que apresentam intersecções com a educação de crianças, adolescentes e jovens.

\section{A confusão da política com os bons sentimentos}

No Brasil, a questão das desigualdades sociais e da pobreza retorna periodicamente ao debate político. Na segunda metade do século XX, vimos esse debate no contexto das reformas de base propostas no governo de Jango; na década de 1970, no bojo das críticas ao chamado "milagre brasileiro"; na década de 1980, como agenda dos movimentos sociais e sindicais; durante a Constituinte, nas definições que ampliavam direitos e, mais recentemente, como preocupação central das propostas do novo governo para as áreas sociais. Parece haver um consenso sobre esse diagnóstico, que denuncia as diversas formas que assume a injustiça social; porém, como apontam Fitoussi e Rosanvallon (1997), os bons sentimentos que animam essa constatação não são acompanhados por um con- 
senso a respeito dos meios e investimentos para superar a situação denunciada.

Outro aspecto interessante desse quadro no país é a diversificação de atores que atuam no campo social e, especialmente, no educacional. Não são mais apenas os profissionais da área que se interessam por ela, como era a norma até alguns anos atrás: empresários, filantropos, organizações não-governamentais, entidades de vários tipos, personalidades; todos têm propostas para a educação e muitos as testam em projetos de pequena escala, mas sempre com grande visibilidade social. Os bons sentimentos se manifestam aqui e ali, geralmente focados em crianças e jovens pobres, mas as políticas resultantes costumam ser erráticas, segmentadas e de baixa cobertura.

\section{0 gosto pela política espetáculo}

Continuando a citar os dois autores franceses, "Tudo sucede como se o essencial fosse proclamar a própria generosidade e dar mostras de boa vontade" (p. 26). A dimensão de espetáculo dos chamados projetos sociais é garantida por parcelas não desprezíveis dos recursos arrecadados, destinadas à divulgação através de material impresso, eventos e noticiário na mídia. As proporções adquiridas por essa divulgação muitas vezes não guardam correspondência com o impacto real dos projetos na população que se quer atingir, ${ }^{1}$ mas o impacto público do que se noticia cumpre a função de proclamar os bons sentimentos e dar a ilusão de que os problemas estão sendo enfrentados de alguma forma.

Mais ainda, a própria lógica do chamado marketing acaba por se impor à formulação do projeto social:

${ }^{1}$ Sandra Zákia de Souza (2000) pesquisou os projetos de parcerias entre empresas e escolas públicas do estado de São Paulo, verificando que, com poucas exceções, caracterizavam-se por atuações pontuais, de caráter assistencialista, com abrangência limitada. Segundo a autora, uma motivação importante que leva as empresas a desenvolverem essas parcerias é a preocupação com sua imagem social nas comunidades onde se instalam. cada vez mais, a formatação de projetos, tanto públicos como privados, obedece aos requerimentos mercadológicos do fomento, à circulação de mercadorias através das técnicas de propaganda. O "recheio" técnico dos programas é feito depois da formulação propagandística, e não o inverso. $\mathrm{O}$ batismo dos programas e o timing de seu lançamento são decididos em outras esferas que não aquelas especializadas em determinado assunto; os especialistas são chamados depois do lançamento, para ajustar e viabilizar o que já ganhou existência virtual na mídia e no cenário político.

\section{A simplificação dos problemas}

Analisando o contexto francês, os dois autores citados mostram como houve um deslocamento no foco da problematização da desigualdade social: passou-se de "uma análise global do sistema (em termos de exploração, repartição etc.) para um enfoque centrado no segmento mais vulnerável da população", os chamados excluídos. Segundo eles, a luta contra a exclusão simplificou a compreensão da dinâmica social, pois se omite o fato de que esse fenômeno resulta de um processo. $\mathrm{O}$ aparente radicalismo esconde o retorno a uma visão mais retrógada do social como remédio para as consequiências mais escandalosas do econômico (Fitoussi \& Rosanvallon, 1997, p. 26-27).

No Brasil, os debates muitas vezes realizam deslocamentos semelhantes. É inegável que a realidade brasileira de desigualdade e pobreza é bastante concreta e dramática. Mais recentemente, essa situação vem sendo nomeada como "fome".

Porém, como mostra Carlos Augusto Monteiro (2003, p. 7-8), pobreza, desnutrição e fome são três coisas diferentes. A pobreza corresponde à condição de não-satisfação de necessidades humanas elementares; as deficiências nutricionais decorrem seja de aporte alimentar deficiente, seja de doenças; a fome pode ser aguda ou crônica, sendo que a fome crônica resulta de alimentação habitual insuficiente para propiciar a energia necessária para a manutenção do organismo e o desempenho das atividades diárias de 
um determinado indivíduo. Associada a essa condição, surge uma das modalidades de desnutrição: a deficiência energética crônica.

O autor dimensiona a proporção da população brasileira considerada pobre, segundo critérios do Projeto Fome Zero, comparativamente ao percentual das pessoas com vinte ou mais anos de idade, com deficiência energética crônica. Para a região Nordeste, esses índices são de $49 \%$ e de 4,2\%, respectivamente, sempre com uma proporção mais alta na zona rural (dados de 1999 e 1997). A porcentagem de crianças desnutridas entre 0 e 5 anos - indicador de desnutrição - nessa região é de $18 \%$, sendo que na zona rural a porcentagem é 25,2\% (Monteiro, 2003, p. 10, 11 e 15 , dados de 1996).

De outra parte, pobreza, desigualdade e exclusão são também três coisas diferentes. Como lembra Aldaíza Sposati (1997, p. 13), o conceito de pobreza é relativo, refletindo os hábitos, valores e costumes de uma sociedade; entretanto, com a globalização, essa noção passa a aproximar-se de uma medida comum. Os indicadores utilizados para estimar o grau de pobreza de uma sociedade partem de medidas quantitativas comparativas, demarcando os estratos sociais que enfrentam os mais baixos padrões de vida. Nesse ponto, a definição de pobreza toca diretamente na questão das desigualdades.

No interior da faixa de pobreza, distingue-se o segmento dos mais destituídos ou indigentes. Barros e colaboradores (2000), utilizando parâmetros da Região Metropolitana de São Paulo, estimaram que em 1998 existiam 50 milhões de pobres no Brasil, sendo 21 milhões deles situados na faixa de indigência. ${ }^{2}$

Dados reproduzidos de uma tabela elaborada por Evaristo Almeida (2000) com base em dados do Programa das Nações Unidas para o Desenvolvimento $(\mathrm{PNUD})^{3}$ dão uma idéia do que significam as diferenças de renda no Brasil, em comparação com outros

${ }^{2}$ Essa estimativa é um pouco superior à do Programa Fome Zero, citada por Monteiro (2003, p. 10).

${ }^{3}$ Também reproduzida por Pedro Demo (1997, p. 6). países. De um total de 16 países, selecionei oito para essa ilustração. A coluna com os dados sobre a renda per capita permite uma comparação entre o nível de riqueza ou pobreza dos países. A diferença entre essa renda média e a renda dos $20 \%$ mais pobres fornece uma medida da desigualdade interna nesses países. Um país, portanto, pode ser mais rico que outro, por exemplo, o Brasil em relação à Índia, mas pode apresentar um indicador de desigualdade três vezes maior.

\section{Tabela 1}

\section{Comparação entre o rendimento médio per capita da população total com o dos $20 \%$ mais pobres em oito países (1993, em US\$)}

\begin{tabular}{|l|c|c|c|}
\hline \multicolumn{1}{|c|}{ País } & $\begin{array}{c}\text { A - Rendimento } \\
\text { médio per } \\
\text { capita da } \\
\text { população total }\end{array}$ & $\begin{array}{c}\text { B - Rendimento } \\
\text { médio } \text { per } \\
\text { capita dos } 20 \% \\
\text { mais pobres }\end{array}$ & $\begin{array}{c}\text { Relação } \\
\text { A/B }\end{array}$ \\
\hline Estados Unidos & 24.240 & 5.814 & 4.2 \\
\hline Holanda & 17.330 & 7.105 & 2.4 \\
\hline Coréia do Sul & 9.630 & 3.563 & 2.7 \\
\hline Chile & 8.400 & 1.386 & 6.1 \\
\hline Brasil & $\mathbf{5 . 3 7 0}$ & $\mathbf{5 6 4}$ & $\mathbf{9 . 5}$ \\
\hline Indonésia & 3.150 & 1.370 & 2.3 \\
\hline Índia & 1.220 & 537 & 2.3 \\
\hline Guiné Bissau & 840 & 88 & 9.5 \\
\hline
\end{tabular}

Fonte: PNUD - 1996 (apud Almeida, 2000, p. 36).

Barros, Henriques e Mendonça (2000) mostram como evoluiu, no Brasil, essa situação de desigualdade. De acordo com a análise dos autores, o Brasil não é um país pobre, mas um país com muitos pobres. Eles demonstram que, por si só, o crescimento econômico não amenizou a extrema desigualdade, nem diminuiu a quantidade de pobres: segundo a Programa Nacional por Amostra de Domicílios (PNAD), entre os anos de 1977 e 1998 a proporção de pobres passou de $39 \%$ para $33 \%$, mas com o crescimento populacional o número absoluto aumentou de $40 \mathrm{mi}-$ lhões para 50 milhões. Para esses autores, a pobreza, entre nós, deve-se mais à desigualdade na distribuição de recursos que à escassez de recursos. Desigualdade que, em suas palavras, "surpreende tanto por sua intensidade como, sobretudo, por sua estabilidade" ao longo do tempo (p. 141). 
A concepção de exclusão envolve questões mais complexas, difíceis de quantificar. A exclusão é mais abrangente que a situação de exploração ou marginalização, e não necessariamente coincide com a condição de pobreza. O sentido da exclusão é tensionado pelo contraste com a inclusão social (Sposati, 1997, p. 21). Traz consigo significados simbólicos de perda de identidade, de não-pertinência ou desfiliação, de negação de acesso. Tratar dos excluídos fora desse quadro mais amplo seria, como apontam Fitoussi e Rosanvallon (1997), retornar a uma visão simplificada e arcaica da sociedade.

Seria importante deter-nos um pouco no exame da exclusão, pois esse processo guarda um significado especial no caso da educação. Por envolver fortes aspectos simbólicos, a falta de acesso à educação é um fator poderoso na determinação das situações de exclusão. Além disso, dependendo de como se vive a escolaridade, a garantia de acesso, por si só, não leva à inclusão social; a qualidade da aprendizagem, as condições de socialização no ambiente escolar podem, ao mesmo tempo que incluem alguns, contribuir para excluir outros, tanto objetivamente, pelas oportunidades diminuídas ou negadas, como subjetivamente, pela vivência de experiências de rejeição social e de não reconhecimento de identidade. ${ }^{4}$

Dubet (2003) examina alguns dos mecanismos de exclusão que são específicos da escola e os tipos de reação que podem provocar nos alunos. Ao mesmo tempo que a escola de massa afirma a igualdade de todos, ela é meritocrática, reforçando a crença no sujeito da modernidade como "o autor de si mesmo". A experiência subjetiva de exclusão na escola é então "vivida potencialmente como uma destruição de si" (p. 40-41). Ou seja, há uma responsabilização dos excluídos pela sua situação. As reações dos alunos podem ser tanto de retraimento - recusa em participar do "jogo" - como de agressividade e violência contra a escola, os professores e os colegas.

${ }^{4}$ Alceu Ferraro (1999) distingue a exclusão da escola da exclusão na escola.

\section{Políticas sociais na sociedade desigual}

Sem ter nunca implantado um sistema universal de bem-estar social, como ocorreu em diversos países europeus no período pós-guerra, o Brasil acumula hoje as dívidas de uma sociedade que se industrializou e urbanizou com os impasses de um país nãohegemônico em um mundo globalizado, em que as políticas neoliberais de esvaziamento da capacidade de intervenção do Estado combinaram-se com a sociedade pós-industrial, onde o desemprego e a exclusão constituem características estruturais. Fazemos parte, como diz José de Sousa Martins, de uma sociedade onde convivem diferentes tempos históricos.

As intersecções entre as políticas assistenciais voltadas para os segmentos mais pobres e as políticas educacionais - por definição universalistas e abertas a todos - são indicadores dessa convivência pouco clara entre as diferentes lógicas dos diversos setores sociais: tradicionalmente, as pontas do sistema educacional são territórios relegados pelos órgãos educacionais e assumidos pela assistência social através de programas focalizados nos segmentos mais pobres da população. Assim, tanto a alfabetização de adultos como as creches sempre foram administradas de forma paralela ao sistema educacional: secretarias de bem-estar social, Legião da Boa Vontade(LBA), Movimento Brasileiro de Alfabetização (MOBRAL), Programa Alfabetização Solidária vêm responsabilizando-se por esses atendimentos, na maior parte das vezes através da terceirização dos serviços por meio de convênios. Mesmo quando atendem faixas etárias correspondentes à obrigatoriedade escolar, os programas correm paralelos às redes escolares, como por exemplo, o atendimento a meninos de rua ou os programas de atividades fora do período escolar. ${ }^{5}$

${ }^{5}$ Com a passagem de alguns desses atendimentos para o âmbito da educação, os órgãos de assistência social tendem a redefinir serviços equivalentes, paralelos e dirigidos às mesmas faixas etárias, geralmente com o qualificativo de alternativos; não se cogita, ao que parece, de um repasse de recursos que acom- 
Algumas políticas sociais foram absorvidas com bastante sucesso pelas redes escolares, como é o caso da merenda escolar, já incorporada ao funcionamento das escolas públicas desde o planejamento e financiamento até as práticas escolares no seu cotidiano. Essa integração é importante, pois a merenda, na maioria dos casos, tornou-se também uma política universal, não discriminando crianças matriculadas numa determinada escola.

\section{O s programas de renda mínima e a escola}

Nos últimos anos, porém, alguns programas de alimentação e de complementação de renda (ou programas de garantia de renda mínima, como são chamados), focalizados exclusivamente nos segmentos mais pobres, vêm sendo implantados junto à população escolar. ${ }^{6}$ Vários desses programas destacam uma fatia dos alunos como via de acesso às famílias beneficiadas. O exemplo mais importante é a Bolsa Escola, mas há outros, como o programa Leve Leite, da Prefeitura de São Paulo, implantado na gestão Maluf e que permanece em funcionamento nas escolas municipais.

Esses programas introduzem, no seio das escolas, uma diferenciação entre os alunos, cujos efeitos ainda estão começando a ser avaliados. Um dos estudos existentes foi realizado por Maria Therezinha de L. Monteiro (2000), no Distrito Federal. Alguns de seus resultados merecem ser destacados aqui.

panhe o repasse de responsabilidades. Ver apresentação de Valdete de Barros Martins, do Ministério da Assistência Social, na Comissão de Educação e Cultura da Câmara dos Deputados, em setembro de 2003.

${ }^{6}$ Em outros países em desenvolvimento isso também vem ocorrendo. No Seminário Internacional Bolsa Escola realizado em Brasília, em 2002, foram citados programas semelhantes em Honduras, Equador, Nicarágua, Moçambique, São Tomé e Príncipe, Argentina, Colômbia, Jamaica, Turquia, Índia e México. O programa do México é dos mais abrangentes, atingindo mais de três milhões de bolsistas (Brasil, Ministério da Educação, 2002).
Em 1995, no governo de Cristóvam Buarque, começou a funcionar em Brasília uma dupla de programas: o Bolsa Escola e a Poupança Escola. A proposta já se encontrava em estudo na Universidade de Brasília desde 1987, de acordo com depoimento de Marcelo Alencar (Brasil, Ministério da Educação, 2002, v. 1, p. 37). A definição da população-alvo deu-se por meio de uma combinação de indicadores para identificar as famílias em situação de risco. Cada família cadastrada recebia um salário mínimo mensal; em troca, deveria garantir a matrícula e a freqüência de seus filhos entre 7 e 14 anos na escola. Ao final de cada ano, as crianças aprovadas recebiam um salário mínimo, que era depositado na Poupança Escola. Ao final da $4^{\mathrm{a}}$ e da $8^{\mathrm{a}}$ séries, o aluno podia sacar parte dos recursos acumulados e, ao final do ensino médio, o restante.

Segundo Evaristo Almeida (2000, p. 132), em 1997, o governo do Distrito Federal gastou 0,6\% de seu orçamento nesse programa, atendendo a $22 \mathrm{mil}$ famílias e 44 mil alunos, que correspondiam a $13 \%$ do total matriculado no ensino fundamental.

O estudo de Monteiro (2000), encomendado pela Secretaria de Educação ao grupo de pesquisa da Universidade Católica de Brasília, investigou 120 crianças e suas famílias, beneficiadas entre 1995 e 1998, e 90 famílias que haviam sido desligadas do programa. As famílias manifestaram uma grande satisfação com o programa, apenas fazendo reparos em relação aos critérios para serem selecionadas. A maioria das crianças (83\%) já estavam matriculadas na escola antes, portanto, mais do que combater o trabalho infantil, o programa servia para complementar a renda familiar, sendo que $50 \%$ dos recursos eram gastos com alimentação.

Os professores e diretores também valorizavam o programa, mas identificavam vários problemas em seu funcionamento, muitos deles confirmados pelos depoimentos das próprias crianças. Segundo eles, na prática, a exigência do programa era percebida como apenas de freqüência à escola, e não incluía o aproveitamento. Os pais vigiavam e chegavam a punir as crianças para obrigá-las a ir à escola, mesmo quando 
doentes, o que indica o peso da responsabilidade dos alunos ao serem vistos como a garantia de renda de suas famílias. Porém, segundo os professores, eles não se preocupavam igualmente com o aproveitamento dos filhos. Como as escolas pouco reprovavam (dentro da concepção da Escola Candanga), apenas encaminhando os alunos com dificuldades para as classes de aceleração, o benefício da Poupança Escola era depositado indistintamente para todos.

$\mathrm{O}$ depoimento das crianças não revelou nenhum sentimento de discriminação entre colegas, em $80 \%$ dos casos; ao contrário, para $40 \%$ das mães, o fato de receber o benefício as tornou mais respeitadas por vizinhos e conhecidos.

Um dos problemas apontados pela pesquisa foi que a permanência no programa só era garantida para aquelas famílias que permaneciam em estado de miserabilidade. Qualquer melhoria na renda familiar era motivo para desligamento. Em muitos casos, o desligamento havia sido provocado por denúncias da própria população. Esse é um problema que aflige também programas de complementação de renda em outros países, pois, numa perspectiva de cidadania, o que se deveria incentivar seria a emancipação das famílias, e não a manutenção de sua situação de dependência.

Evaristo Almeida (2000) analisou os dados sobre programas e projetos ainda não implantados de complementação de renda no Brasil, associados ou não à educação. Ele resume os dados de levantamento realizado por Sposati em 1997, o qual realizou uma caracterização das propostas existentes. Uma das conclusões é que são justamente os estados e municípios mais ricos que apresentam maior número de propostas; só no estado de São Paulo estavam concentradas $62 \%$ delas. A maioria das propostas focalizava a família como destinatária, e não o indivíduo, como propõe o projeto do senador Eduardo Suplicy (1992). Um dado especialmente interessante é a intersecção que a maioria das propostas possuía com a educação, direta ou indiretamente: $82 \%$ utilizavam a faixa etária dos filhos como critério de elegibilidade, sendo que a maioria definia a faixa de 0 a 14 anos; $70 \%$ estabeleciam a freqüência escolar das crianças de 7 a 14 anos como condição para a família receber o benefício.

Outro estudo citado por Almeida é uma avaliação coordenada por Sonia Draibe sobre o programa implantado pela prefeitura de Campinas em 1995. Diferente do programa de Brasília, este se vinculava à Secretaria de Assistência Social e não à Secretaria de Educação. Seu foco eram as famílias mais pauperizadas, com crianças entre 0 e 14 anos, em situação de risco, entre outros critérios. A freqüência à escola era apenas uma entre outras exigências, tais como comparecer a uma reunião mensal de orientação e o incentivo à utilização de outros serviços da área social.

Draibe (apud Almeida, 2000) constatou resultados bastante positivos nas famílias atendidas: em média, os recursos dessas famílias foram triplicados, sendo que, também lá, a metade do benefício foi utilizada para alimentação; os depoimentos colhidos revelam melhorias na higiene pessoal, no vestuário e na auto-estima, com muitas pessoas fazendo planos para o futuro, apesar de o programa prever o desligamento das famílias após 12 ou 24 meses.

Como problema, a pesquisa apontou a insuficiente cobertura do programa, que não conseguiu atingir todas as famílias na faixa de renda prevista, não tendo gasto o montante de recursos reservados nos anos de 1995 a 1997, correspondentes a 1\% do orçamento municipal.

Muitas semelhanças podem ser encontradas entre a realidade verificada em Campinas e Brasília: nas duas cidades, cerca de metade das famílias beneficiadas era monoparental, chefiadas por mulheres; $50 \%$ dos recursos recebidos foram destinados à alimentação e, em segundo lugar, para vestuário e material escolar. Note-se que a falta de vestuário e de material escolar muitas vezes são motivos que levam as famílias muito pobres a deixarem de enviar seus filhos à escola.

Almeida (2000) também fornece alguns dados sobre outros sete programas implantados até aquele ano em Ribeirão Preto, Salvador, Vitória, Boa Vista, Santos, Belo Horizonte e Jundiaí.

A maioria dos programas municipais estabelece um prazo mínimo de residência na cidade para a fa- 
mília poder se candidatar a eles. Sendo programas isolados, coloca-se essa necessidade de preservar o município. Como nota Almeida, no caso de um programa federal, não precisaria existir essa limitação. ${ }^{7}$

No plano federal, foram implantados, nos últimos anos, vários programas de complementação de renda, muitos deles sendo agora integrados na proposta da Bolsa Família.

A Lei Orgânica de Assistência Social (LOAS), promulgada em 1993 e modificada anos depois, definiu o Benefício de Prestação Continuada, que prevê o pagamento de um salário mínimo mensal a pessoas portadoras de deficiência e a idosos com 70 anos ou mais que estejam abaixo da linha de indigência. A regulamentação excluiu do benefício as crianças de 0 a 6 anos em situação de risco, que estavam previstas como parte do público-alvo na LOAS. ${ }^{8}$ Segundo Almeida (2000), até o final de 1999 o programa concedeu um milhão de benefícios, sendo dois terços para portadores de deficiência.

Em 1996, foi criado no nível federal o Programa de Erradicação do Trabalho Infantil (PETI), também chamado de Vale Cidadania. Esse programa de renda mínima teve uma abrangência geográfica limitada, visando atingir crianças que trabalham em carvoarias e alguns tipos de plantação. De acordo com Almeida (2000), em 1999, atendeu 145 mil crianças em 13 estados, uma cobertura modesta, pois, segundo dados do PNUD/Instituto de Pesquisa Econômica Aplicada (IPEA) para 1996, havia no país três milhões de crianças, entre 10 e 14 anos, trabalhando.

${ }^{7}$ Em intervenção durante o Seminário Internacional Bolsa Escola, a Secretária de Educação de Caririaçu, Ceará, contou que antes da implantação do programa federal o programa municipal provocava a "invasão" da cidade por famílias dos municípios próximos (Brasil, Ministério da Educação, 2002, v. 1, p. 41).

${ }^{8}$ Recentemente, o Ministério da Educação anunciou um programa voltado para as crianças pobres de 0 a 3 anos, em que se previa um pagamento às mães que não enviassem seus filhos à creche. Devido às críticas recebidas e principalmente à falta de verbas para financiá-lo, acabou excluído do Plano Plurianual (PPA).
Alguns anos depois, ${ }^{9}$ em 2001, foi implantado o Programa Bolsa Escola pelo Ministério da Educação, financiado pelo Fundo de Combate à Pobreza, que também provê recursos para os demais programas de transferência de renda no nível federal.

O programa federal funciona de maneira descentralizada: os municípios realizam o cadastramento das famílias e devem organizar ações educativas para as crianças atendidas; as mães recebem um cartão magnético que agiliza o recebimento de 15 reais mensais por criança, até um máximo de três crianças por família; são previstos Conselhos de Controle Social com participação da comunidade, em cada município. No final de 2002, o programa atingia 5.545 municípios brasileiros, segundo dados oficiais. A meta declarada era atingir aproximadamente 6 milhões de famílias, ou 11 milhões de crianças. Alguns estados e municípios passaram também a desenvolver programas que complementam o desembolso federal.

Outros programas de transferência de renda foram inaugurados no final do governo FHC: o Bolsa Alimentação, do Ministério da Saúde, que tem seu público-alvo definido como gestantes, mulheres em fase de amamentação e crianças até 6 anos; o Agente Jovem de Desenvolvimento, o Auxílio Gás etc.

A fragmentação e o paralelismo desses programas, agora acrescidos do Fome Zero, levaram à atual proposta, em estudos no governo federal, de um programa de auxílio às famílias que funcione de forma integrada e unifique os múltiplos cadastros de beneficiários: o Bolsa Família.

\footnotetext{
${ }^{9}$ A publicação que divulga o Seminário Internacional Bolsa
} Escola, realizado em Brasília em 2002, menciona a data de 2001 como sendo aquela em que a lei $\mathrm{n}^{\circ} 10.219$ foi sancionada pelo Executivo. Almeida (2000) cita a lei $\mathrm{n}^{\circ}$ 9.533, aprovada pelo Congresso em 1998, que criou o Programa de Garantia da Renda Mínima. O senador Lúcio Alcântara relata que foi esse o projeto transformado no Bolsa Escola Nacional (Brasil, Ministério da Educação, 2002, v. 1, p. 52). 


\section{Algumas questões a serem pesquisadas}

Qual o impacto que esses programas têm tido sobre as escolas públicas? As avaliações realizadas geralmente preocupam-se mais em medir os impactos junto às famílias. Para além da frequiência, que mudanças podem ser observadas, seja no aproveitamento das crianças, seja no funcionamento das escolas? Mais importante ainda, qual o impacto nas políticas educacionais? Estaríamos trocando o apoio às famílias por um menor apoio às escolas?

Discutir melhor essas questões parece importante, pois os programas de complementação de renda, associados ou não à educação, vieram para ficar. Contam com apoio político, ganham destaque entre os organismos internacionais e, mais importante, correspondem a necessidades sociais prementes e dramáticas. Os resultados junto às famílias beneficiadas têm se mostrado, no geral, positivos, e assim o incentivo à sua expansão tende a crescer.

Uma das questões que mais vem preocupando o setor educacional é a possibilidade, bastante real, desses programas serem financiados com verbas que deveriam ser destinadas ao sistema escolar público. $\mathrm{O}$ município de São Paulo optou por esse caminho, ao desvincular parte da verba destinada à educação para financiar programas de fornecimento de uniformes e material escolar às crianças das escolas municipais.

Do ponto de vista do administrador público, a tentação é grande. Os resultados de uma boa rede escolar pública só se percebem a longo prazo e não são evidentes a todos. O ensino é uma atividade contínua que, dia após dia e ano após ano, precisa ser cuidada e apoiada. A escola pública é aberta a todos; em um país populoso e com déficits educacionais acumulados, isso significa que sempre há muitos batendo à sua porta. Além disso, o sistema público, ao crescer e se complexificar, fortalece também as corporações de profissionais de educação, geralmente bem organizadas e difíceis de contentar.

Em comparação, os programas de combate à pobreza apresentam uma visibilidade muito mais rápida e disseminada. Costumam ser descontínuos no tempo e variar muito no espaço. Não são políticas universalistas, sendo possível circunscrever seus beneficiários, o que permite que por vezes programas com pequena cobertura ganhem destaque incompatível com suas reais dimensões. Os quadros profissionais necessários não formam uma grande corporação; é possível administrá-los sem grande aparato burocrático.

No entanto, mesmo que se garantam fontes independentes de financiamento, esses programas significam um desafio novo para as escolas, sobre o qual ainda não refletimos muito.

Em primeiro lugar, se forem eficientes, vão ajudar a trazer para dentro do sistema aquelas crianças, adolescentes e jovens com os quais as escolas ainda não aprenderam a trabalhar. ${ }^{10}$ Nesse sentido, se não forem acompanhados de maiores investimentos nas escolas, provavelmente podem intensificar uma crise que já vem sendo vivida com a democratização crescente do acesso à educação, que ocorre, felizmente, no país.

Segundo, a disseminação de uma concepção de política de complementação de renda baseada em direitos de cidadania, que cria obrigações também para os beneficiados e que não deveria suscitar discriminação na vida social, será provavelmente lenta, numa sociedade que ainda convive com práticas clientelistas e ainda confunde política social com assistencialismo e direito com favor. A recente incorporação das creches nas secretarias de educação tem revelado quão arraigados são esses preconceitos na área educacional. Parece urgente que esse debate seja introduzido nos meios educacionais, nos espaços de formação de educadores e na formulação de propostas educativas.

Em terceiro lugar, é importante reafirmar, e mesmo proclamar de forma audível na sociedade quais são as finalidades últimas da educação e sua fundamental importância na construção do desenvolvimento e de uma sociedade mais democrática. A educação de

${ }^{10}$ Ver artigo de Patrícia R. Redondo (1999) sobre a vivência de crianças pauperizadas em escola situada em favela de Buenos Aires. 
qualidade proporciona um dos únicos bens que se torna indissociável da pessoa; as políticas de combate à pobreza podem ser importantes para permitir que as crianças mais pobres delas se beneficiem, mas não são capazes, por si sós, de garantir uma inclusão social verdadeira.

Como defendem Fitoussi e Rosanvallon (1997), as desigualdades sociais não podem ser entendidas exclusivamente na perspectiva do direito de receber determinados bens e serviços. Seria preciso contemplar também o que eles chamam de direitos de integração, que são aqueles que permitem que os indivíduos sejam cidadãos ativos, com pleno direito de viver em sociedade. O papel de um sistema de educação democrático é fundamental nessa perspectiva.

MARIA MALTA CAMPOS, pedagoga, doutora em sociologia pela Universidade de São Paulo, com pós-doutorado em educação na Universidade de Stanford, nos Estados Unidos, é pesquisadora do Departamento de Pesquisas Educacionais da Fundação Carlos Chagas e professora do Programa de Pós-Graduação em Educação - Currículo da PUC de São Paulo. Foi presidente da ANPEd de 1995 a 1999. Publicou numerosos artigos em periódicos, assim como vários capítulos de livros, e é co-autora dos livros Creches e pré-escolas no Brasil e Creches e pré-escolas no hemisfério Norte, ambos pela Editora Cortez. Atualmente desenvolve estudos sobre conceitos de qualidade na educação básica e sobre políticas de educação infantil. E-mail: mcampos@fcc.org.br

\section{Referências bibliográficas}

ALMEIDA, Evaristo, (2000). Programas de garantia de renda mínima: inserção social ou utopia? São Paulo: EDUC/FAPESP. BARROS, Ricardo Paes de, HENRIQUES, Ricardo, MENDONÇA, Rosane, (2000). Desigualdade e pobreza no Brasil: retrato de uma estabilidade inaceitável. Revista Brasileira de Ciências Sociais, v. $15, \mathrm{n}^{\circ} 42$, p. 123-142, fev.
BRASIL, Ministério da Educação, (2002). Bolsa Escola Federal. 3 v. Brasília: MEC/PNUD.

DEMO, Pedro, (1997). Menoridade dos mínimos sociais. Encruzilhada da assistência social no mundo de hoje. Brasília: SASMPAS/FUNDAP (mimeo.).

DUBET, François, (2003). A escola e a exclusão. Cadernos de Pesquisa, no 119, p. 29-45, jul.

FERRARO, Alceu Ravanello, (1999). Diagnóstico da escolarização no Brasil. Revista Brasileira de Educação, no 12, p. 2247, set.-dez.

FITOUSSI, Jean-Paul, ROSANVALLON, Pierre, (1997). La nиеva era de las desigualdades. Buenos Aires: Manantial.

MARTINS, Valdete de Barros, (2003). Atenção à criança de 0 a 6 anos. Trabalho apresentado no Seminário Nacional Financiamento da Educação Infantil. Brasília: Câmara dos Deputados, setembro (mimeo.).

MONTEIRO, Carlos Augusto, (2003). A dimensão da pobreza, da desnutrição e da fome no Brasil. Estudos Avançados, v. 17, $\mathrm{n}^{\mathrm{o}} 48$, p. 7-20, maio-ago.

MONTEIRO, Maria Therezinha de Lima, (2000). O impacto social do Programa Bolsa-Escola no Distrito Federal. Estudos em Avaliação Educacional, no 22, p. 37-91, jul.-dez.

REDONDO, Patrícia Raquel, (1999). Imaginando otros futuros: niños y escuelas en contextos de pobreza en la Argentina de los noventa. Educação e Pesquisa, v. 25, nº 1, p. 21-34, jan.-jul.

SOUSA, Sandra M. Zákia de, (2000). Parceria escola-empresa no Estado de São Paulo: mapeamento e caracterização. Educação \& Sociedade, ano XXI, no 70, p.171-188, abr.

SPOSATI, Aldaíza, (1997). Mínimos sociais e seguridade social: uma revolução da consciência da cidadania. Brasília: SASMPAS/FUNDAP (mimeo.).

SUPLICY, Eduardo, (1992). Programa de garantia de renda mínima. Brasília: Senado Federal.

Recebido em outubro de 2003 Aprovado em outubro de 2003 